\title{
Magnitude of HIV and syphilis seroprevalence among pregnant women in Gondar, Northwest Ethiopia: a cross-sectional study
}

This article was published in the following Dove Press journal:

HIVIAIDS - Research and Palliative Care

2 June 2015

Number of times this article has been viewed

\section{Mulugeta Melku' \\ Asmarie Kebede ${ }^{2}$ \\ Zelalem Addis ${ }^{3}$}

'Department of Hematology and Immuohematology, School of

Biomedical and Laboratory Sciences, ${ }^{2}$ Department of Nursing, University of Gondar Teaching Hospital, ${ }^{3}$ Department of Medical Microbiology, School of Biomedical and Laboratory Sciences, College of Medicine and Health Sciences, University of Gondar, Gondar, Ethiopia
Correspondence: Mulugeta Melku Department of Hematology and Immuohematology, School of Biomedical and Laboratory Sciences, College of Medicine and Health Sciences, University of Gondar, PO Box 196, Gondar 6200, Ethiopia Tel +25I 9 I008452I

Email mulugeta.melku@gmail.com
Background: Human immunodeficiency virus (HIV) and syphilis are major public health problems in sub-Saharan Africa, causing numerous adverse pregnancy outcomes. The aim of study was to assess the magnitude of HIV and syphilis seroprevalence among pregnant women at University of Gondar Teaching Hospital.

Method: The study was conducted between March and May, 2012. Sociodemographic data were collected through face-to-face interview. HIV1/2 was tested following current national HIV1/2 testing algorithm. Syphilis infection was also tested using the rapid plasm reagin test for screening and Treponema pallidum hemagglutination as a confirmatory test. Both bivariate and multivariate analysis were used to identify factors associated with HIV and syphilis seroprevalence from selected sociodemographic variables.

Results: Of 300 women, 31 (10.33\%), eleven (3.7\%), and three (1\%) were seroreactive for HIV, syphilis, and HIV-syphilis coinfection, respectively. High seroprevalence of HIV was found in women ages 25-30 years (13.4\%), and women whose husbands attended primary school (19.7\%). Syphilis was high in women occupationally housewives (15.2\%) and whose husbands were illiterate (11.5\%). HIV was associated with husband illiteracy (AOR [adjusted odds ratio] of $4.13,95 \% \mathrm{CI}$ [confidence interval] [1.01, 16.95]) and primary educational level of husbands $(\mathrm{AOR}[95 \% \mathrm{CI}]=3.83[1.50,9.90])$, whereas syphilis was associated with illiteracy of husband (AOR [95\% CI] $=7.25[1.74,30.30]$ ).

Conclusion: Seroprevalence of HIV and syphilis was high. Low husband educational status was a risk factor for HIV and syphilis. Therefore, substantial efforts have to be made to reinforce prevention strategies and to screen as early as possible to prevent mother-to-child and further horizontal transmission.

Keywords: HIV, magnitude, seroprevalence, syphilis

\section{Introduction}

Sexually transmitted infections (STIs) including human immunodeficiency virus/ acquired immune deficiency syndrome (HIV/AIDS) are an emerging public health concern, especially in developing countries. ${ }^{1-3}$ Globally, an estimated 1.3 billion people are suffering from STIs. ${ }^{4,5}$ The magnitude of STIs is high in all regions, with highest rates in World Health Organization (WHO) regions of America and Africa. ${ }^{6,7}$ In Africa, a significant portion of pregnant women have been suffering from STIs, and it is the major cause of maternal and perinatal morbidity. ${ }^{8-10}$ HIV and syphilis infections are epidemiologically interrelated, and coinfection is common.

Despite the efforts made to eliminate syphilis, the disease still continues to be a cause of morbidity and mortality worldwide. ${ }^{9,11}$ For several decades, syphilis had 
been considered eradicated throughout the Western world. However, its incidence is now on the rise again, and it becomes one of a major health concern. This has been linked with the rapidly rising number of HIV/AIDS positive people and population migration. ${ }^{12}$ Globally, an estimated 12 million people test positive for syphilis each year, of which over 2 million are pregnant women. ${ }^{13,14}$ In Ethiopia though, there are few institutional-based, cross-sectional studies published; still, there is a lack of comprehensive national epidemiological information about syphilis. ${ }^{10,15-17}$ Despite the initiative launched by the WHO to eliminate congenital syphilis with the aim to achieve at list $90 \%$ antenatal syphilis screening and adequate treatment for approximately $90 \%$ seropositive pregnant women, the achievement is low due to low antenatal care (ANC) coverage. ${ }^{13}$

Syphilis during pregnancy has been associated with numerous adverse pregnancy outcomes such as perinatal death and disability, stillbirth, prematurity, low birth weight, neonatal mortality, and congenital syphilis. ${ }^{18-20}$ Also, it facilitates mother-to-child transmission of HIV. ${ }^{21,22}$

HIV is another major cause of death in women of reproductive age globally. ${ }^{23}$ Sub-Saharan Africa is the region where $90 \%$ of the total number of pregnant women with HIV have been residing. ${ }^{24}$ It is also estimated that one-quarter of deaths of pregnant and postpartum women in sub-Saharan Africa are attributable to $\mathrm{HIV}^{4,25}$

HIV during pregnancy is associated with various undesirable consequences for the mother, fetus, and neonates such as maternal death, abortion, stillbirth, and low birth weight. ${ }^{26-30}$ Though the use of antiretroviral therapy reduces the rate of mother-to-child transmission of HIV, vertical transmission of HIV and antiretroviral therapy-induced adverse pregnancy outcomes are becoming and emerging challenges. ${ }^{31-33}$

Prevention and control of STIs and improving access to STI services are critical components of the global strategies to achieve the Millennium Development Goals (MDGs) in the areas of maternal and child health (MDGs 4 and 5) and combating HIV (MDG 6). ${ }^{7}$ As part of these strategies, antenatal screening of HIV and syphilis plays a vital role in reducing vertical and horizontal transmission and related adverse pregnancy outcomes. However, ANC coverage and utilization is low in Ethiopia (54\%), and there is also remarkably wide inequities of ANC utilization between urban and rural areas, across economic and educational stratas. ${ }^{34,35}$ Hence, the aim of this study was to assess the magnitude of HIV and syphilis seroprevalence among ANC attendees in the University of Gondar Teaching Hospital.

\section{Methods}

A cross-sectional study was conducted from March to May, 2012, to determine seroprevalence of HIV, syphilis, and HIV-syphilis coinfection among pregnant women. During the study period, pregnant women who were attending ANC service in the University of Gondar Teaching Hospital were invited to participant in the study.

A single population proportion formula,

$$
\left[n=(Z \alpha / 2)^{2} p(1-p) / d^{2}\right]
$$

was used to estimate the sample size. Though there are few previous studies done in this particular setting regarding seroprevalence of HIV and syphilis, the sample calculated in these studies was considered small for generating statistical inference. ${ }^{15,16}$ Due to this reason, 50\% seroprevalence was used for sample size calculation with the intention of getting maximum sample size. Records of daily flow of pregnant women for ANC utilization indicate that, on average, 30 pregnant women visit the hospital for ANC utilization each day. During the study period, approximately 1,350 pregnant women were estimated to visit ANC clinic. Since the population during the study period was below 10,000 , the sample size correction formula was applied. Then, a total of 300 pregnant women were included in the study. The study participants were chosen at regular intervals from their sequence of ANC visit using systematic random sampling techniques. The sampling interval for this research was $1,350 / 300=4.5$. It was approximated to four by assuming nonrespondents from the total 1,350 estimated pregnant women. The first sample order to be included in the study was selected by lottery from the order of four pregnant women. The third order was selected as a first sample. Thereafter, at every forth interval pregnant women were included in the study until the total sample was achieved.

A face-to-face interview using a structured, pretested questionnaire was employed to obtain data about sociodemographic, obstetric, and medical conditions. After the interview, a blood sample was drawn for HIV and syphilis testing. HIV infection was investigated following the national HIV1/2 testing algorithm currently in use (KHB Shanghai Kehua Bio-engineering Co, LTD, Shanghai, People's Republic of China) as screening test, Stat-PAK (Chembio Diagnostic Systems, Inc., New York, NY, USA) as a confirmatory test for positive samples, and Uni-Gold ${ }^{\mathrm{TM}}$ (Trinity Biotech Plc, Bray, Ireland) as a tie-breaker test 
when samples gave discordant results in the first two tests. These HIV testing methods were immunochromatographic assays. Performance evaluation studies demonstrated that the sensitivity and specificity of Stat-PAK ranged from $97.6 \%$ to $100 \%$ and $99.8 \%$ to $100 \%$, respectively. ${ }^{36-38} \mathrm{KHB}$ has a sensitivity ranging from $94 \%$ to $100 \%$ and specificity ranging from $99.1 \%$ to $100 \%{ }^{36,37,39}$ Similarly, the performance evaluation studies conducted in Africa also claimed that the sensitivity and specificity of Uni-Gold ranged from $98.5 \%$ to $100 \%$ and $99 \%$ to $100 \%$, respectively. ${ }^{37,38,40,41}$ Syphilis seroreactivity was tested using the rapid plasma reagin (RPR) test (Human GmbH-Wiesbaden, Germany) as per the manufacturer's instructions and recommendations. All RPR positive sera/plasma were subjected to the Treponema pallidum hemagglutination (TPHA) test (Guangzhou Wondfo Biotech Co, Ltd, Guangzhou, People's Republic of China) as a confirmatory test. Pregnant women who tested positive for both RPR and TPHA were diagnosed as having syphilis infection.

All information collected was coded and entered to EPI Info version 3.5.3 and then transferred to SPSS version 20 statistical package for analysis. Study participants were characterized according to the variables using descriptive and summary statistics and were presented in tables. Seroprevalence of the respective infections was defined as the percentage of positive cases for each serology, and the standard error and $95 \%$ confidence interval $(95 \% \mathrm{CI})$ were calculated for each prevalence value. The association between HIV and syphilis with selected sociodemographic variables was tested with the logistic regression model. The magnitude of associations was assessed using odds ratios with respective $95 \%$ CI. Explanatory variables having a $P$-value less than 0.2 in univariate binary logistic regression were included in multivariate analysis to control confounders. Variables having a $P$-value less than 0.05 in multivariate binary logistic regression model were considered to be statistically significant.

Participation was voluntary, with written consent provided by each pregnant woman after the purpose and importance of the study was explained to each participants. The study was approved by the Institutional Review Board of the University of Gondar. Results were communicated with clinicians working in the ANC unit for appropriate management. Pregnant women who were reactive for syphilis were treated with standard treatment, and they were also advised not to have sexual contact unless their sexual partner gets tested of syphilis and treated. Pregnant women who were seropositive for HIV were linked to the prevention of mother-to-child transmission clinic for specific follow-up and proper management.

\section{Results}

A total of 300 pregnant women who were attending ANC service between March and May, 2012, were screened for HIV and syphilis. The seroprevalence of HIV, syphilis, and HIV-syphilis coinfection were $10.33 \%$ (95\% CI: 6.7, 14), $3.7 \%$ (95\% CI: $1.7,6.0)$, and $1 \%(95 \%$ CI: $0.1,2.2)$, respectively.

Table I Sociodemographic characteristics of study participants

\begin{tabular}{|c|c|c|}
\hline Variable & Frequency & Percentage \\
\hline \multicolumn{3}{|l|}{ Age } \\
\hline$\leq 20$ years & 37 & 12.3 \\
\hline $2 \mathrm{I}-25$ years & 109 & 36.3 \\
\hline $26-30$ years & 109 & 36.3 \\
\hline $30-35$ years & 22 & 7.3 \\
\hline$>35$ years & 23 & 7.7 \\
\hline \multicolumn{3}{|l|}{ Residence } \\
\hline Rural & 60 & 20 \\
\hline Urban & 240 & 80 \\
\hline \multicolumn{3}{|l|}{ Marital status } \\
\hline Single & 13 & 4.3 \\
\hline Married & 282 & 94 \\
\hline Other* & 5 & 1.7 \\
\hline \multicolumn{3}{|l|}{ Maternal educational status } \\
\hline Illiterate & 69 & 23 \\
\hline Primary school & 53 & 17.7 \\
\hline Secondary school & 105 & 35 \\
\hline Tertiary & 73 & 24.3 \\
\hline \multicolumn{3}{|l|}{ Husband educational status } \\
\hline Do not have husband & 18 & 6 \\
\hline Illiterate & 52 & 17.3 \\
\hline Primary school & 61 & 20.3 \\
\hline Secondary school & 91 & 30.4 \\
\hline Tertiary & 78 & 26 \\
\hline \multicolumn{3}{|l|}{ Occupation } \\
\hline Housewife & 193 & 64.3 \\
\hline Government employee & 26 & 8.7 \\
\hline Private sector employee & 62 & 20.7 \\
\hline Other** & 19 & 6.3 \\
\hline \multicolumn{3}{|l|}{ Family monthly income } \\
\hline$<\mathrm{I}, 000$ ETB & 71 & 23.7 \\
\hline I,000-I,500 ETB & 101 & 33.7 \\
\hline I,50I-2,800 ETB & 55 & 18.3 \\
\hline$>2,800$ ETB & 73 & 24.3 \\
\hline \multicolumn{3}{|l|}{ Family size } \\
\hline$\leq 2$ & 122 & 40.7 \\
\hline $3-4$ & 123 & 41 \\
\hline$\geq 5$ & 55 & 18.3 \\
\hline
\end{tabular}

Notes: *Includes divorced and widowed; **includes students, farmers, merchants, and day laborers.

Abbreviation: ETB, Ethiopian birr. 


\section{Sociodemographic characteristic of study participants}

The age ( \pm standard deviation) of the study population averaged $27.4( \pm 5.6)$. The majority 282 (94\%), 240 (80.0\%), 193 (64.3\%), and 172 (57.4\%) were married, urban residents, housewives by occupation, having a family monthly income less than 1,501 ETB (1 US dollar is nearly equivalent to 20 ETB), respectively. Moreover, 169 (56.4\%) of the study participants had attended secondary and tertiary education, and $55(18.3 \%)$ of them were living in a family consisting of five or more family members (Table 1).

\section{Characteristics of participants associated with HIV and syphilis seropositivity}

Of the total $31 \mathrm{HIV}$ seropositive pregnant women, 13 (42\%) were secundigravidae, whereas, of the total of eleven syphilis seroreactive pregnant women, five (45\%) of them were 3-4 gravida. Five (16.13\%) of HIV and one (9\%) syphilis seropositive pregnant women had a history of spontaneous abortion. Concerning the medical conditions, of the total HIV seropositive pregnant women, $24(77.42 \%)$ of them were infected with one or more intestinal parasite. Furthermore, of the total syphilis seropositive, seven (63.64\%) were infected with intestinal parasite (Table 2).

The magnitude of HIV seroprevalence was high in women age $25-30$ years; $13.4 \%$ of them were seropositive. Surprisingly, all HIV seropositive pregnant women were married. A high proportion of the pregnant women who were urban residents (11.2\%), had a family size of three to four members (15.4\%), had a family monthly income less than 1,000 ETB (11.3\%), and had attended secondary school (16.2\%) were HIV seropositive. HIV infection was significantly more prevalent in those women whose husbands had attended primary school (crude odds ratio $[\mathrm{COR}][95 \% \mathrm{CI}]=2.71[1.18,6.25]$ ) and had a family size of three to four members (COR $[95 \% \mathrm{CI}]=1.85$ $[1.02,3.90])$. HIV infection was not associated with maternal educational status, occupation, age, residence, and history of abortion (Table 3).

Regarding the magnitude of syphilis seropositivity, high seroprevalence was found in pregnant women who were occupationally housewives (15.2\%), whose husbands were illiterate $(11.5 \%)$, whose age was older than 30 years $(11.1 \%)$, and who were living in a family having five and more members $(9.1 \%)$. Syphilis infection was significantly more prevalent in pregnant women older than 30 years (COR $[95 \% \mathrm{CI}]=6.49[1.21,33.3])$ and in those women whose husbands were illiterate $(\mathrm{COR}[95 \% \mathrm{CI}]=7.20[1.72,30.30])$. Syphilis seropositivity was not associated with maternal educational status, occupation, residence, family size, family monthly income, or history of abortion (Table 4).

\section{Multivariate models for factors associated with HIV and syphilis seropositivity}

To control the possible confounders and assess independently associated factors for HIV and syphilis infection, multivariate logistic regression analysis was done. Seroprevalence of HIV remained significantly associated with illiteracy of husband (AOR [adjusted odds ratio] $[95 \% \mathrm{CI}]=4.13$

Table 2 Some obstetric, anthropometric, and medical conditions of pregnant women in relation to seropositivity for HIV and syphilis

\begin{tabular}{|c|c|c|c|c|}
\hline \multirow[t]{2}{*}{ Variable } & \multicolumn{2}{|c|}{ HIV seroreactivity } & \multicolumn{2}{|c|}{ Syphilis seroreactivity } \\
\hline & $\begin{array}{l}\text { Reactive } \\
\text { n (\%) }\end{array}$ & $\begin{array}{l}\text { Nonreactive } \\
\text { n (\%) }\end{array}$ & $\begin{array}{l}\text { Reactive } \\
\text { n (\%) }\end{array}$ & $\begin{array}{l}\text { Nonreactive } \\
\text { n (\%) }\end{array}$ \\
\hline \multicolumn{5}{|l|}{ Gravidity } \\
\hline Primigravidae & II (35.48) & II 8 (43.87) & $3(27.27)$ & $126(43.60)$ \\
\hline Secundigravidae & $13(4 \mid .94)$ & $64(23.79)$ & I (9.09) & $76(26.30)$ \\
\hline $3-4$ gravida & $7(22.58)$ & $57(21.19)$ & $5(45.45)$ & $59(20.42)$ \\
\hline$\geq 5$ gravida & $0(0)$ & $30(11.15)$ & $2(18.18)$ & $28(9.69)$ \\
\hline \multicolumn{5}{|l|}{ History of abortion } \\
\hline Yes & $5(16.13)$ & $36(13.38)$ & I (9.09) & $40(13.84)$ \\
\hline No & $26(83.87)$ & $233(86.62)$ & $10(90.91)$ & $249(86.16)$ \\
\hline \multicolumn{5}{|l|}{ Gestational age } \\
\hline Ist trimester & $\mathrm{I}(3.23)$ & $7(2.60)$ & $0(0)$ & $8(2.77)$ \\
\hline 2nd trimester & $13(41.94)$ & $85(31.60)$ & $2(18.18)$ & $96(33.23)$ \\
\hline $3 r d$ trimester & $17(54.83)$ & $177(65.80)$ & $9(81.82)$ & $185(64.00)$ \\
\hline \multicolumn{5}{|l|}{ Body mass Index } \\
\hline Underweight & $8(25.8 \mathrm{I})$ & $27(10.04)$ & $0(0)$ & $35(12.11)$ \\
\hline Normal & $15(48.39)$ & $170(63.20)$ & $9(81.82)$ & $176(60.90)$ \\
\hline Overweight & $7(22.58)$ & $63(23.43)$ & $2(18.18)$ & $68(23.53))$ \\
\hline Obese & I (3.23) & $9(3.35)$ & $0(0)$ & $10(3.46)$ \\
\hline
\end{tabular}

Abbreviation: HIV, human immunodeficiency virus. 
Table 3 Seroprevalence of HIV and bivariate and multivariate analysis according to selected sociodemographic characteristics and medical conditions of study participants

\begin{tabular}{|c|c|c|c|c|c|}
\hline \multirow[t]{2}{*}{ Variable } & \multicolumn{2}{|c|}{ HIV seroreactivity } & \multirow[t]{2}{*}{ COR $(95 \% \mathrm{Cl})$} & \multirow[t]{2}{*}{$P$-value } & \multirow[t]{2}{*}{ AOR $(95 \% \mathrm{Cl})$} \\
\hline & $\begin{array}{l}\text { Reactive } \\
\text { n (\%) }\end{array}$ & $\begin{array}{l}\text { Nonreactive } \\
\text { n (\%) }\end{array}$ & & & \\
\hline \multicolumn{6}{|l|}{ Age } \\
\hline$<25$ years & $7(6.6)$ & $99(93.4)$ & $0.72(0.2,2.6 \mathrm{I})$ & 0.21 & \\
\hline $25-30$ years & $20(13.4)$ & $129(86.6)$ & $1.59(0.5 \mathrm{I}, 4.93)$ & & \\
\hline$>30$ years & $4(8.9)$ & 41 (9l.I) & 1 & & \\
\hline \multicolumn{6}{|l|}{ Residence } \\
\hline Urban & $27(11.2)$ & $213(88.8)$ & I.78 $(0.6,5.3)$ & 0.303 & \\
\hline Rural & $4(6.7)$ & $56(93.3)$ & 1 & & \\
\hline \multicolumn{6}{|l|}{ Marital status } \\
\hline Married & $3 I(I I)$ & $25 \mathrm{I}(89)$ & & & \\
\hline Other* & $0(0)$ & $18(100)$ & & & \\
\hline \multicolumn{6}{|l|}{ Maternal educational status } \\
\hline Below secondary school & $8(6.6)$ & II 4 (93.4) & $0.78(0.26,2.35)$ & 0.055 & $0.33(0.08,1.33)$ \\
\hline Secondary school & $17(16.2)$ & $88(83.8)$ & $2.16(0.81,5.78)$ & & $1.54(0.54,4.38)$ \\
\hline Tertiary school & $6(8.2)$ & $67(91.8)$ & 1 & & 1 \\
\hline \multicolumn{6}{|l|}{ Husband educational status } \\
\hline Illiterate & $5(9.6)$ & $47(90.4)$ & I.I $8(0.40,3.44)$ & 0.125 & $4.13(1.01,16.95)^{\dagger}$ \\
\hline Primary school & $12(19.7)$ & $49(80.3)$ & $2.71(1.18,6.25)$ & & $3.83(1.50,9.90)^{\dagger \dagger}$ \\
\hline Secondary and above & $14(8.3)$ & $155(91.7)$ & 1 & & 1 \\
\hline \multicolumn{6}{|l|}{ Occupation } \\
\hline Housewife & $20(10.4)$ & I 73 (89.6) & $1.32(0.47,3.68)$ & 0.807 & \\
\hline Government employee & $5(8.1)$ & $57(91.9)$ & 1 & & \\
\hline Private sector employee & $3(I I .5)$ & $23(88.5)$ & $1.5(0.33,6.76)$ & & \\
\hline Other** & $3(I 5.8)$ & $16(84.2)$ & $2.14(0.46,9.9)$ & & \\
\hline \multicolumn{6}{|l|}{ Family monthly income } \\
\hline$<\mathrm{I}, 000 \mathrm{ETB}$ & $8(I I .3)$ & $63(88.7)$ & $\mathrm{I} .03(0.4 \mathrm{I}, 2.6)$ & 0.845 & \\
\hline I,000-I,500 ETB & $9(8.9)$ & $92(91.1)$ & $0.8(0.33,1.92)$ & & \\
\hline$>I, 500 \mathrm{ETB}$ & $14(10.9)$ & $114(89.1)$ & 1 & & \\
\hline \multicolumn{6}{|l|}{ Family size } \\
\hline$\leq 2$ & II (9.00) & III (91.00) & 1 & 0.043 & 1 \\
\hline $3-4$ & $19(15.4)$ & $104(84.6)$ & $1.85(1.02,3.90)$ & & $1.97(0.85,4.57)$ \\
\hline$\geq 5$ & $\mathrm{I}(\mathrm{I} .8)$ & $54(98.2)$ & $0.19(0.02,1.49)$ & & $0.23(0.03,1.85)$ \\
\hline \multicolumn{6}{|l|}{ History of abortion } \\
\hline Yes & $5(12.2)$ & $36(87.8)$ & $1.25(0.45,3.45)$ & 0.674 & \\
\hline No & $26(10)$ & $233(90)$ & 1 & & \\
\hline
\end{tabular}

Notes: *Includes single, divorced, and widowed; **includes students, farmers, merchants, and day laborers; Bold numerical values indicate significance in bivariate analysis; Significance ${ }^{\dagger}(P<0.05)$ and ${ }^{\dagger \dagger}(P<0.01)$ in multivariate analysis.

Abbreviations: $\mathrm{AOR}$, adjusted odds ratio; $\mathrm{Cl}$, confidence interval; $\mathrm{COR}$, crude odds ratio; $\mathrm{ETB}$, Ethiopian birr; HIV, human immunodeficiency virus.

$[1.01,16.95])$ and primary educational level of husband (AOR $[95 \% \mathrm{CI}]=3.83[1.50,9.90])$ (Table 3). Likewise, women who had illiterate husbands (AOR $[95 \% \mathrm{CI}]=7.25[1.74,30.30])$ were more likely to be seropositive for syphilis (Table 4).

\section{Discussion}

In the current study, the overall seroprevalence of HIV among pregnant women was 31 (10.33\%). This prevalence was consistent with previous studies conducted at the same study area, Gondar teaching hospital $(9.6 \%)^{15}$ and Gondar health centers $(11.9 \%) .{ }^{16}$ Contrary to this, it was higher than studies conducted in Bahir Dar, Ethiopia (6.6\%), ${ }^{42}$ a rural area of Tanzania (2\%), ${ }^{43}$ rural Northern Tanzania (2\%), ${ }^{44}$ Democratic Republic of the Congo (1.9\%), ${ }^{45}$ and Southern
Ethiopia (1.8\%). ${ }^{10}$ The difference might be attributed to the variation in sexual behavior risk and other contributing risk factors for HIV transmission between these population. High HIV seroprevalence was found in those age 25-30 years (13.4\%). This was in line with a previous report from Gondar, Ethiopia, where $13 \%$ of pregnant women age 25-29 years old were seropositive for HIV. ${ }^{15}$ Women in this age group are highly vulnerable to HIV infection because this age group comprises a sexually active segment of the population.

The seroprevalence of syphilis in the current study was $3.7 \%$, which was comparable to studies conducted in Madagascar (3\%), ${ }^{9}$ Bangladesh (3\%), ${ }^{46}$ and Addis Ababa, Ethiopia $(2.9 \%)^{47}$ In contrast, it was higher than the studies done in Gondar health centers, Ethiopia $(2.3 \%),{ }^{16}$ Tanzania $(1.6 \%),{ }^{43}$ 
Table 4 Seroprevalence of syphilis and bivariate and multivariate analysis according to selected sociodemographic characteristics and medical conditions of study participants

\begin{tabular}{|c|c|c|c|c|c|}
\hline \multirow[t]{2}{*}{ Variable } & \multicolumn{2}{|c|}{ Syphilis seroreactivity } & \multirow[t]{2}{*}{ COR $(95 \% \mathrm{Cl})$} & \multirow[t]{2}{*}{$P$-value } & \multirow[t]{2}{*}{ AOR $(95 \% \mathrm{Cl})$} \\
\hline & $\begin{array}{l}\text { Reactive } \\
\text { n (\%) }\end{array}$ & $\begin{array}{l}\text { Nonreactive } \\
\text { n (\%) }\end{array}$ & & & \\
\hline \multicolumn{6}{|l|}{ Age } \\
\hline$<25$ years & $2(1.9)$ & $104(98.1)$ & I & 0.032 & 1 \\
\hline $25-30$ years & $4(2.7)$ & $145(97.3)$ & $1.43(0.26,8.0)$ & & $1.28(0.23,7.25)$ \\
\hline$>30$ years & $5(11.1)$ & $40(88.9)$ & $6.49(1.21,33.3)$ & & $3.62(0.62,22.22)$ \\
\hline \multicolumn{6}{|l|}{ Residence } \\
\hline Urban & $7(2.9)$ & $233(97.1)$ & I & 0.179 & 1 \\
\hline Rural & $4(6.7)$ & $56(93.3)$ & $5.59(0.67,8.4)$ & & $1.02(0.21,5.00)$ \\
\hline \multicolumn{6}{|l|}{ Maternal educational status } \\
\hline Below secondary school & $7(5.7)$ & II 5 (94.3) & $2.65(0.76,9.26)$ & 0.127 & $0.75(0.13,4.48)$ \\
\hline Secondary and above & $4(2.2)$ & $174(97.8)$ & I & & I \\
\hline \multicolumn{6}{|l|}{ Husband educational status } \\
\hline Illiterate & $5(11.5)$ & $46(88.5)$ & $7.2(1.72,30.30)$ & 0.007 & $7.25(1.74,30.30)^{* *}$ \\
\hline Primary school & $2(3.3)$ & $59(96.7)$ & $1.88(0.31,11.5)$ & & I.88 (0.3I, II.50) \\
\hline Secondary and above & $3(1.8)$ & $166(98.2)$ & $\mathrm{I}$ & & 1 \\
\hline \multicolumn{6}{|l|}{ Occupation } \\
\hline Housewife & $10(15.2)$ & $183(84.8)$ & $5.78(0.73,45.45)$ & 0.091 & $7.19(0.88,50.00)$ \\
\hline Other* & I (0.9) & $106(99.1)$ & 1 & & $\mathrm{I}$ \\
\hline \multicolumn{6}{|l|}{ Family monthly income } \\
\hline$<1,000$ ETB & $4(5.6)$ & $67(95.4)$ & $3.76(0.67,21.28)$ & 0.132 & $1.75(0.11,11.76)$ \\
\hline I,000-1,500 ETB & $5(5.00)$ & $96(95.00)$ & $3.28(0.62,17.24)$ & & $2.54(0.43,14.90)$ \\
\hline$>1,500 \mathrm{ETB}$ & $2(1.6)$ & $126(98.4)$ & I & & I \\
\hline \multicolumn{6}{|l|}{ Family size } \\
\hline$\leq 2$ & $3(2.5)$ & $119(97.5)$ & I & 0.087 & I \\
\hline $3-4$ & $3(2.4)$ & $120(97.6)$ & $0.99(0.20,5.00)$ & & $0.57(0.09,3.40)$ \\
\hline$\geq 5$ & $5(9.10)$ & $50(90.90)$ & $3.97(0.91,17.24)$ & & I.II $(0.16,7.69)$ \\
\hline \multicolumn{6}{|l|}{ History of abortion } \\
\hline Yes & I (2.4) & $40(97.6)$ & $0.62(0.08,5.00)$ & 0.656 & \\
\hline No & $10(3.9)$ & $259(96.1)$ & $\mathrm{I}$ & & \\
\hline
\end{tabular}

Notes: *Other occupations include: private sector employees, governmental employees, students, farmers, merchants, and day laborers. Bold numerical values indicate significance in bivariate analysis; **significance $(P<0.0 \mathrm{I})$ in multivariate analysis.

Abbreviations: AOR, adjusted odds ratio; $\mathrm{Cl}$, confidence interval; COR, crude odds ratio; ETB, Ethiopian birr.

and Gondar teaching hospital, Ethiopia (1\%). ${ }^{15}$ However, it was lower than previous studies conducted in Northwest Ethiopia (13.7\%), ${ }^{17}$ Southwestern Nigeria (10\%), ${ }^{48}$ and Northeast Brazil (7.7\%). ${ }^{49}$ The variation might be the result of differences in culture, socioeconomic status, prevention and control measures, risk factors, level of awareness, and methods used for diagnosis.

In this study, low educational level of husbands (including illiteracy and primary school) was the risk factor for high seroprevalence of HIV. Similarly, having an illiterate husband increased the risk of being seropositive for syphilis. In our study, pregnant women whose husbands had no formal education were at seven times greater risk of being seropositive for syphilis compared to pregnant women having husband with secondary school and above educational attainment. This finding was consistent with a study conducted in Bangladesh. ${ }^{46}$ Husbands with low educational levels may not have adequate knowledge about transmission mechanisms of HIV and syphilis, so they may be exposed to the diseases unintentionally. This has been further compounded by low levels of maternal education, low socioeconomic status, low access to health care facilities, gender inequality, and high rate of risky extramarital sexual practices of husbands. ${ }^{50,51}$ This indicates that improvement of education level in the population should have a positive impact in reducing the disease.

\section{Limitations of the study}

One of the limitations of this study is that it is a tertiary hospital-based, cross-sectional design, which might not represent the general population of pregnant women. Another limitation is the use of only serological tests for the diagnosis of HIV and syphilis, which may lead to false positivity and negativity and, ultimately, underestimate or overestimate of the results of our study. Furthermore, since sexual related issues were socially sensitive, risk factors other than selected 
sociodemographic characteristic were not assessed in the present study.

\section{Conclusion}

This study revealed that HIV and syphilis were prevalent among pregnant women, indicating that they are significant public health problems. This indicates the need to enhance antenatal screening to reduce and ultimately prevent vertical and horizontal transmission of HIV and syphilis. Likewise, appropriate strategies should be devised for prevention and control of HIV, syphilis, and other sexually transmitted diseases in women of reproductive age and general population. Low educational level of husbands was found to be a factor that significantly increases the risk of being infected with HIV and syphilis among pregnant women. Therefore, improvement of education level in the general population may play an important role in the prevention of HIV and syphilis. Moreover, societal factors that contribute to HIV and syphilis transmission need to be further studied in the general population, which will be helpful to prevent future HIV and syphilis transmission in the general population.

\section{Author contributions}

MM participated in designing the study, performing the data collection and statistical analysis, and was a lead author of the paper. AK and ZA participated in the study design and helped in drafting the paper. All authors contributed toward data analysis, drafting and revising the paper and agree to be accountable for all aspects of the work. All authors read and approved of the final paper.

\section{Acknowledgments}

We wish to thank the hospital staff who actively participated during the data collection process. We are also grateful to and wish to thank the pregnant women for their voluntary participation in this study. Lastly, we would like to thank the University of Gondar and the University of Gondar Teaching Hospital for financial and logistical support.

\section{Disclosure}

The authors report no conflicts of interest in this work.

\section{References}

1. Msuya SE, Uriyo J, Hussain A, et al. Prevalence of sexually transmitted infections among pregnant women with known HIV status in northern Tanzania. Reprod Health. 2009;6:4.

2. Minichiello V, Rahman S, Hussain R. Epidemiology of sexually transmitted infections in global indigenous populations: data availability and gaps. Int J STD AIDS. 2013;24(10):759-768.
3. The World Bank. Sexually transmitted infections in developing countries: current concepts and strategies on improving STI prevention, treatment, and control [webpage on the Internet]. Washington, DC: The World Bank; 2008. Available from: http://documents.worldbank. org/curated/en/2008/03/9068926/sexually-transmitted-infectionsdeveloping-countries-current-concepts-strategies-improving-stiprevention-treatment-control. Accessed August 20, 2014.

4. UNAIDS. Global report: UNAIDS Report on the Global AIDS Epidemic 2013. Geneva: UNAIDS; 2013. Available from: http://www. unaids.org/sites/default/files/en/media/unaids/contentassets/documents/ epidemiology/2013/gr2013/UNAIDS_Global_Report_2013_en.pdf. Accessed August 20, 2014.

5. World Health Organization. Sexually Transmitted Infections (STIs): The Importance of a Renewed Commitment to STI Prevention and Control in Achieving Global Sexual and Reproductive Health. Geneva: World Health Organization; 2013. Available from: http://apps.who.int/ iris/bitstream/10665/82207/1/WHO_RHR_13.02_eng.pdf. Accessed August 20, 2014.

6. World Health Organization. Global Incidence and Prevalence of Selected Curable Sexually Transmitted Infections - 2008. Geneva: World Health Organization; 2012. Available from: http://apps.who. int/iris/bitstream/10665/75181/1/9789241503839_eng.pdf. Accessed August 20, 2014.

7. World Health Organization. Baseline Report on Global Sexually Transmitted Infection Surveillance 2012. Geneva; World Health Organization; 2013. Available from: http://apps.who.int/iris/bitstream/10665/85376/1/9789241505895_eng.pdf. Accessed August 20, 2014.

8. Chiduo M, Theilgaard ZP, Bakari V, et al. Prevalence of sexually transmitted infections among women attending antenatal clinics in Tanga, northeastern Tanzania. Int J STD AIDS. 2012;23(5): 325-329.

9. Frickmann H, Schwarz NG, Girmann M, et al. Serological survey of HIV and syphilis in pregnant women in Madagascar. Trop Med Int Health. 2013;18(1):35-39.

10. Ramos JM, Toro C, Reyes F, Amor A, Gutiérrez F. Seroprevalence of HIV-1, HBV, HTLV-1 and Treponema pallidum among pregnant women in a rural hospital in Southern Ethiopia. J Clin Virol. 2011;51(1): 83-85.

11. Watson-Jones D, Oliff M, Terris-Prestholt F, et al. Antenatal syphilis screening in sub-Saharan Africa: lessons learned from Tanzania. Trop Med Int Health. 2005;10(9):934-943.

12. Oswal S, Lyons G. Syphilis in pregnancy. Contin Educ Anaesth Crit Care Pain. 2008;8(6):224-227.

13. World Health Organization. The global elimination of congenital syphilis: rationale and strategy for action [webpage on the Internet]. Geneva: World Health Organization; 2007. Available from: http:// www.who.int/reproductivehealth/publications/rtis/9789241595858/en/. Accessed August 24, 2014.

14. Schmid G, Rowley J, Samuelson J, et al. Global incidence and prevalence of four curable sexually transmitted infections (STIs): new estimates from WHO. In: Proceedings of the 2nd Global HIV/AIDS Surveillance Meeting (ISSTDR); June-July 2009; London, UK; 2009.

15. Mulu A, Kassu A, Tessema B, et al. Seroprevalence of syphilis and HIV-1 during pregnancy in a teaching hospital in northwest Ethiopia. Jpn J Infect Dis. 2007;60(4):193-195.

16. Tiruneh M. Seroprevalence of multiple sexually transmitted infections among antenatal clinic attendees in Gondar Health Center, northwest Ethiopia. Ethiop Med J. 2008;46(4):359-366.

17. Azeze B, Fantahun M, Kidan KG, Haile T. Seroprevalence of syphilis amongst pregnant women attending antenatal clinics in a rural hospital in north west Ethiopia. Genitourin Med. 1995;71(6): 347-350.

18. Qin J, Yang T, Xiao S, Tan H, Feng T, Fu H. Reported estimates of adverse pregnancy outcomes among women with and without syphilis: a systematic review and meta-analysis. PLoS One. 2014;9(7): e102203. 
19. Gomez GB, Kamb ML, Newman LM, Mark J, Broutet N, Hawkes SJ. Untreated maternal syphilis and adverse outcomes of pregnancy: a systematic review and meta-analysis. Bull World Health Organ. 2013;91(3):217-226.

20. Mullick S, Watson-Jones D, Beksinska M, Mabey D. Sexually transmitted infections in pregnancy: prevalence, impact on pregnancy outcomes, and approach to treatment in developing countries. Sex Transm Infect. 2005;81(4):294-302.

21. Mwapasa V, Rogerson SJ, Kwiek JJ, et al. Maternal syphilis infection is associated with increased risk of mother-to-child transmission of HIV in Malawi. AIDS. 2006;20(14):1869-1877.

22. Hayes R, Watson-Jones D, Celum C, van de Wijgert J, Wasserheit J. Treatment of sexually transmitted infections for HIV prevention: end of the road or new beginning? AIDS. 2010;24(Suppl 4):S15-S26.

23. World Health Organization. Women and Health: Today's Evidence Tomorrow's Agenda. Geneva: Gender: World Health Organization; 2009. Available from: http://whqlibdoc.who.int/hq/2009/WHO_IER_ MHI_STM.09.1_eng.pdf.

24. UNAIDS. Regional Fact Sheet 2012. Sub-Saharan Africa. Geneva: UNAIDS; 2012. Available from: http://www.unaids.org/sites/default/ files/en/media/unaids/contentassets/documents/epidemiology/2012/ gr2012/2012_FS_regional_ssa_en.pdf.

25. Kendall T, Danel I. Research and Evaluation Agenda for HIV and Maternal Health in sub-Saharan Africa: Women and Health Initiative Working Paper No 1. Boston, MA: Women and Health Initiative, Harvard School of Public Health; 2014. Available from: http://www.mhtf.org/wp-content/ uploads/sites/17/2014/01/WorkingPaper_MaternalHealth-HIV1.pdf.

26. Thayaparan P, Kawsar M, Balachandran T. Adverse pregnancy outcomes in HIV positive women. A study from a District General Hospital in the UK. Retrovirology. 2012;9(Suppl 1):P138.

27. Kebede B, Andargie A, Gebeyehu A. Birth outcome and correlates of low birth weight and preterm delivery among infants born to HIV-infected women in public hospitals of Northwest Ethiopia. Health. 2013;5(7A4):25-34.

28. Zeleke BM, Zelalem M, Mohammed N. Incidence and correlates of low birth weight at a referral hospital in Northwest Ethiopia. Pan Afr Med J. 2012;12:4

29. Ngene NC, Moodley J, Songca P, et al. Maternal and fetal outcomes of HIV-infected and non-infected pregnant women admitted to two intensive care units in Pietermaritzburg, South Africa. S Afr Med J. 2013;103(8):543-548.

30. Kim HY, Kasonde P, Mwiya M, et al. Pregnancy loss and role of infant HIV status on perinatal mortality among HIV-infected women. $B M C$ Pediatr. 2012;12:138.

31. Prestes-Carneiro LE. Antiretroviral therapy, pregnancy, and birth defects: a discussion on the updated data. HIV AIDS (Auckl). 2013;5:181-189.

32. Watts DH, Huang S, Culnane M, et al. Birth defects among a cohort of infants born to HIV-infected women on antiretroviral medication. $J$ Perinat Med. 2011;39(2):163-170.

33. Tricco AC, Antony J, Angeliki VA, et al. Safety and effectiveness of antiretroviral therapies for HIV-infected women and their infants and children: protocol for a systematic review and network meta-analysis. Syst Rev. 2014;3:51.

34. Central Statistical Agency [Ethiopia] and ICF International. Ethiopian Demographic and Health Survey 2011. Ethiopia and Calverton, MD: Addis Ababa; 2012:120. Available from: http://dhsprogram.com/pubs/ pdf/FR255/FR255.pdf. Accessed September 12, 2014.
35. Yesuf EA, Calderon-Margalit R. Disparities in the use of antenatal care service in Ethiopia over a period of fifteen years. BMC Pregnancy Childbirth. 2013;13:131.

36. World Health Organization. HIV Assays: Operational Characteristics (Phase 1). Report 14/Simple/Rapid Tests. Geneva: World Health Organization; 2004. Available from: http://www.who.int/diagnostics_ laboratory/publications/en/hiv_assays_rep_14.pdf. Accessed September 12, 2014.

37. Shanks L, Siddiqui M, Kliescikova J, et al. Evaluation of HIV testing algorithms in Ethiopia: the role of the tie-breaker algorithm and weakly reacting test lines in contributing to a high rate of false positive HIV diagnoses. BMC Infect Dis. 2015;15(1):39.

38. Lyamuya EF, Aboud S, Urassa WK, et al. Evaluation of simple rapid HIV assays and development of national rapid HIV test algorithms in Dar es Salaam, Tanzania. BMC Infect Dis. 2009;9:19.

39. Kimotho J, Ng'ang'a Z, Nyairo E, et al. Laboratory evaluation of the validity of the current HIV testing algorithm in Kenya. Am J Internal Medicine. 2015;3(1):23-27.

40. Piwowar-Manning EM, Tustin NB, Sikateyo P, et al. Validation of rapid HIV antibody tests in 5 African countries. J Int Assoc Physicians AIDS Care (Chic). 2010;9(3):170-172.

41. von Knorring N, Gafos M, Ramokonupi M, Jentsch U; MDP Team. Quality control and performance of HIV rapid tests in a microbicide clinical trial in rural KwaZulu-Natal. PLoS One. 2012;7(1):e30728.

42. Zenebe Y, Mulu W, Yimer M, Abera B. Sero-prevalence and risk factors of hepatitis B virus and human immunodeficiency virus infection among pregnant women in Bahir Dar city, Northwest Ethiopia: a cross sectional study. BMC Infect Dis. 2014;14:118.

43. Yahya-Malima KI, Evjen-Olsen B, Matee MI, Fylkesnes K, Haarr L. HIV-1, HSV-2 and syphilis among pregnant women in a rural area of Tanzania: prevalence and risk factors. BMC Infect Dis. 2008;8:75.

44. Yahya-Malima KI, Olsen BE, Matee MI, Fylkesnes K. The silent HIV epidemic among pregnant women within rural Northern Tanzania. BMC Public Health. 2006;6:109.

45. Kinoshita-Moleka R, Smith JS, Atibu J, et al. Low prevalence of HIV and other selected sexually transmitted infections in 2004 in pregnant women from Kinshasa, the Democratic Republic of the Congo. Epidemiol Infect. 2008;136(9):1290-1296.

46. Nessa A, Islam MN, Ashraf F, et al. Seroprevalence of Treponema Pallidum antibody among pregnant population of Bangladesh. $J$ Obstet Gynaecol Res. 2011;37(11):1625-1630.

47. Kebede E, Chamiso B. Prevalence of syphilis in pregnancy in Addis Ababa. East Afr Med J. 2000;77(4):212-216.

48. Ojo DA, Oyetunji IAO. Sero-prevalence of syphilis among pregnant women In Osogbo in Southwestern Nigeria. ASSET Series B. 2007;6(1): 61-65.

49. Araújo MA, de Freitas SC, de Moura HJ, Gondim AP, da Silva RM. Prevalence and factors associated with syphilis in parturient women in Northeast, Brazil. BMC Public Health. 2013;13:206.

50. Gupta S, Gupta R, Singh S. Seroprevalence of HIV in pregnant women in North India: a tertiary care hospital based study. BMC Infect Dis. 2007;7:133.

51. Mumah JN, Jackson-Smith D. Do the factors associated with female HIV infection vary by socioeconomic status in Cameroon? J Biosoc Sci. 2014;46(4):431-448.
HIV/AIDS - Research and Palliative Care

\section{Publish your work in this journal}

HIV/AIDS - Research and Palliative Care is an international, peerreviewed open-access journal focusing on advances in research in HIV, its clinical progression and management options including antiviral treatment, palliative care and public healthcare policies to control viral spread. The journal welcomes original research, basic science,

\section{Dovepress}

clinical \& epidemiological studies, reviews \& evaluations, expert opinion \& commentary, case reports \& extended reports. The manuscript management system is completely online and includes a very quick and fair peer-review system. Visit http://www.dovepress.com/ testimonials.php to read real quotes from published authors. 